\title{
EDUCACIÓN SUPERIOR EN IBEROAMÉRICA. INFORME 2007. CINDA
}

El Centro Interuniversitario de Desarrollo (CINDA) llevó a cabo un proyecto destinado a analizar los principales aspectos de la educación superior en Iberoamérica. Dirigido por Iván Lavados y coordinado por José Joaquín Brunner, el proyecto se recoge en un completo informe, publicado en 2007, que pretende contribuir al diálogo, al análisis y la proyección del espacio iberoamericano de educación superior, a partir de quince estudios nacionales ${ }^{1}$ referidos a los siguientes temas:

- Los desafíos de la educación superior en el espacio iberoamericano.

- La plataforma institucional de los sistemas.

- El acceso y las oportunidades que ofrece la educación superior.

- La formación del capital humano avanzado.

- El rol de la universidad en las actividades de investigación y desarrollo.

- El financiamiento de la educación superior.

- El gobierno y la gestión de los sistemas e instituciones.

- El aseguramiento de la calidad en el ámbito de la educación superior.

Con el propósito de promover la comparación internacional, los resultados del proyecto incluyen cinco países de fuera del área iberoamericana, pertenecientes a diferentes regiones del mundo: Australia, Canadá, Gran Bretaña y la República de Corea, como

1 Los estudios nacionales contemplados en el informe corresponden a Argentina, Bolivia, Brasil, Chile, Colombia, Costa Rica, Ecuador, México, Panamá, Perú, República Dominicana, Uruguay, Venezuela, España y Portugal. Puerto Rico presentó también un estudio, realizado en conjunto con los demás informes nacionales, pero no fue posible incorporarlo porque faltan datos comparables para este país en las fuentes estadísticas utilizadas. En todo caso, dicho estudio se encuentra incluido en el disco compacto que acompaña al informe. 
representantes del grupo de países de alto ingreso, y Estonia, un país de ingreso medio alto y de elevada competitividad.

Cada capítulo presenta una breve introducción al tema, seguida de datos estadísticos relevantes y antecedentes extraídos de los respectivos estudios nacionales.

El informe enfatiza en el análisis de la educación superior como un componente de la estructura social que define un contexto desde el cual deben medirse sus avances y aportes.

Entre otros aspectos, analiza:

- La diversificación experimentada por los sistemas de educación superior, tanto en sentido horizontal (presencia creciente de nuevos proveedores privados, expansión geográfica de las instituciones y diferenciación interna de las mismas) como vertical (desarrollo de instituciones universitarias y no universitarias, o presencia, dentro de las mismas instituciones, de distintos niveles de formación).

- El crecimiento de la matrícula que, si bien se cuadruplicó en los últimos treinta años, presenta rasgos que lo ponen en perspectiva: la desigualdad en la participación por quintiles de ingreso, su concentración en programas de cinco años o más, en áreas tales como administración, derecho, ciencias sociales, educación y servicios sociales o personales.

- La formación y volumen del capital humano avanzado, destacando el número y tasa de graduados que producen las instituciones de educación superior, la organización de procesos formativos, la eficiencia interna de dichos procesos, la distribución de graduados por área de especialización, su inserción laboral y los beneficios económicos asociados a los diplomas de educación superior.

- En el ámbito de la investigación y desarrollo (I \& D), el hecho de que, en la región, un pequeño pero estratégico núcleo de universidades constituyen el centro de gravedad de estas actividades. El reporte señala el riesgo que implica la escasa 
inversión en ciencia y tecnología pero, además, muestra que otros problemas, tales como la forma de organización de las actividades de I \&D, la escasa vinculación con el sector productivo, la ausencia de prioridades gubernamentales y la fragilidad de los programas de formación de nuevos investigadores son significativos al momento de superar el rezago de la región en este ámbito.

- El problema del financiamiento de la educación superior. El informe recoge las experiencias de los distintos países, tanto desde el punto de vista del destino de los recursos como de su origen y utilización.

- La diversidad de formas de organizar el gobierno y la gestión de las instituciones de educación superior. Se hace cargo de los debates fundamentales referidos a los principios de colegialidad democrática y sus formas de implementación y efectos en las universidades públicas, y a la conformación del gobierno corporativo en las instituciones privadas.

- El aseguramiento de la calidad, como uno de los cambios más visibles en el desarrollo del sector. Este informe muestra cómo cada país iberoamericano ha ido trazando su propio rumbo y explorando qué modalidades de evaluación y acreditación se acomodan mejor a sus necesidades y tradiciones, ordenamiento legal y prácticas académicas. Existe una gran variedad de experiencias que sirven de base para los procesos de aprendizaje e intercambio promovidos desde la Red Iberoamericana para la Acreditación de la Calidad de la Educación Superior (RIACES), creada en 2003.

En síntesis, el informe constituye un instrumento de enorme valor para el análisis de los temas y problemas asociados al desarrollo de la educación superior. La recopilación de antecedentes nacionales, asociada al análisis comparativo de las distintas realidades, permite identificar diversas estrategias, evaluar su eficacia relativa y efectuar un aprendizaje efectivo a partir de las experiencias de la región. La versión completa de los informes nacionales en un disco compacto, así como el conjunto de elementos de información y recursos complementarios 
de consulta contenidos en cada capítulo, permiten profundizar en los aspectos más relevantes para los lectores.

María José Lemaitre Directora Académica Instituto Internacional para el Aseguramiento de la Calidad (IAC)

Centro Interuniversitario del Desarrollo (CINDA) mjlemaitre@cinda.cl 